\title{
Vasopressor mechanisms in acute aortic coarctation hypertension
}

\author{
H.C. Salgado, \\ R. Fazan Jr. and \\ M.C.O. Salgado
}

\author{
Departamentos de Fisiologia e Farmacologia, \\ Faculdade de Medicina de Ribeirão Preto, Universidade de São Paulo, \\ 14049-900 Ribeirão Preto, SP, Brasil
}

\section{Correspondence \\ H.C. Salgado \\ Departamento de Fisologia \\ Faculdade de Medicina de \\ Ribeirão Preto \\ Universidade de São Paulo \\ 14049-900 Ribeirão Preto, SP \\ Brasil \\ Fax: 55 (016) 633-0017 \\ E-mail: hcsalgad@fmrp.usp.br. \\ Presented at the International Symposium "Neuroendocrine \\ Control of Body Fluid Homeostasis", \\ Ribeirão Preto, SP, Brasil, \\ August 17-20, 1996. \\ Research supported by FAPESP and CNPq. \\ Received September 2, 1996 Accepted October 8, 1996}

\begin{abstract}
Angiotensin II (ANG II) and vasopressin (AVP) act together with the mechanical effect of aortic constriction in the onset of acute aortic coarctation hypertension. Blockade of ANG II and AVP $\mathrm{V}_{1}$ receptors demonstrated that ANG II acts on the prompt $(5 \mathrm{~min})$ rise in pressure whereas AVP is responsible for the maintenance (30-45 $\mathrm{min}$ ) of the arterial pressure elevation during aortic coarctation. Hormone assays carried out on blood collected from conscious rats submitted to aortic constriction supported a role for ANG II in the early stage and a combined role for both ANG II and AVP in the maintenance of proximal hypertension. As expected, a role for catecholamines was ruled out in this model of hypertension, presumably due to the inhibitory effect of the sinoaortic baroreceptors. The lack of afferent feedback from the kidneys for AVP release from the central nervous system in rats with previous renal denervation allowed ANG II to play the major role in the onset of the hypertensive response. Median eminence-lesioned rats exhibited a prompt increase in proximal pressure followed by a progressive decline to lower hypertensive levels, revealing a significant role for the integrity of the neuroaxis in the maintenance of the aortic coarctation hypertension through the release of AVP. In conclusion, the important issue raised by this model of hypertension is the likelihood of a link between some vascular territory - probably renal - below the coarctation triggering the release of AVP, with this vasoconstrictor hormone participating with Ang II and the mechanical effect of aortic constriction in the acute aortic coarctation hypertension.
\end{abstract}

\section{Mechanical vs renal factor}

For a long time two schools of thought have attributed different mechanisms to chronic aortic coarctation hypertension. Whereas one school suggested that the mechanical effect of aortic constriction was the main factor promoting high blood pressure (1-3), others (4-6) argued that a renal factor was involved in the arterial pressure elevation. However, it was only in 1968 (7) that
Key words

- Aortic coarctation

- Vasopressin

- Angiotensin

- Renal afferences

- Hypertension studies on young dogs with hypertension induced by chronic aortic coarctation hypertension provided a clear-cut demonstration that both factors, i.e., mechanical and renal factors, were operative in this model for hypertension. Later, these observations were confirmed in adult dogs submitted to aortic constriction, indicating a major role for the renal mechanisms in the development of hypertension, associated with a role played by aortic constriction (8). 
The experimental model of aortic coarctation hypertension has been extensively studied under both acute and chronic conditions. Since the sixties the rat has become one of the most important species employed for studies of several hypertensive models including coarctation of the aorta (9). Chronic experiments have been carried out on rats $(10,11)$ and especially on $\operatorname{dogs}(12,13)$. Acute experiments lasting minutes or a few hours have been performed mainly on anesthetized dogs (14).

We developed in our laboratory a technique for long-term implantation of a pneumatic cuff around large arterial vessels (aorta and carotid artery) of rats which permits the study of cardiovascular responses to procedures such as aortic constriction (15). Using this technique in conscious intact and bilaterally nephrectomized rats submitted to acute (45 min) partial aortic constriction above the renal arteries, we demonstrated that nephrectomized rats exhibited a blunted hypertensive response compared to intact rats, which was mainly due to the mechanical effect of aortic constriction imposed by the pneumatic cuff (16). Because in that study the aortic resistance was not measured and the degree of constriction of the aorta was monitored by keeping the distal pressure to the occlusion at a fixed level $(50 \mathrm{mmHg})$, this observation was confirmed more recently (17) in conscious intact or bilaterally nephrectomized rats by measuring the change in aortic flow with a pulsed Doppler flowmeter, a technique that provides a reliable measurement of the change in aortic resistance. Nevertheless, removal of the kidneys eliminates hypertensive mechanisms other than the reninangiotensin system (RAS), such as $\mathrm{R}_{2}$ renal chemoreceptors which are activated by reduction of renal blood flow and by changes in the interstitial ionic environment (18-20). In addition, it has been reported that in anesthetized rats afferent information from the kidneys selectively alters the activity of vasopressin (AVP) neurosecretory cells of the hypothalamus (supraoptic cells) and may contribute to a reflex pathway through which the kidneys may alter the release of AVP $(21,22)$.

\section{The renin-angiotensin system and vasopressin}

Based on previous studies from our laboratory $(16)$ and others $(23,24)$ showing that the RAS plays a pivotal role in the onset of the hypertensive response to aortic constriction and that activation of renal afferences might trigger the release of $\operatorname{AVP}(21,22)$, we designed a protocol in which angiotensin II (ANG II) receptors were blocked with saralasin and AVP $\mathrm{V}_{1}$ vascular receptors were blocked with $\mathrm{d}\left(\mathrm{CH}_{2}\right)_{5} \mathrm{Tyr}(\mathrm{Me})$ AVP (Manning's compound) during aortic constriction (25). In that study, experiments carried out using this pharmacological approach demonstrated that conscious unrestrained rats treated with Manning's compound presented a prompt rise in carotid pressure similar to that of untreated (control) rats but, in contrast to this group, the pressure started to decline. Rats treated with saralasin presented a delay in the onset of hypertension right after coarctation, but attained values similar to those for control rats. It is noteworthy that rats treated with both antagonists showed a blunted carotid pressure elevation throughout the period of coarctation, resembling the change in pressure observed in nephrectomized rats, which was attributed almost exclusively to the mechanical factor of the constriction (16). For a more direct evaluation of the contributions of these humoral mechanisms we determined the changes of plasma renin activity (PRA), plasma AVP and plasma catecholamines (epinephrine and norepinephrine) after 15 and $45 \mathrm{~min}$ of aortic constriction (26). Plasma AVP concentration did not differ from that observed in control rats after 15 min of coarctation, but showed a five-fold increase after $45 \mathrm{~min}$. On the other hand, PRA was already significant- 
ly increased after $15 \mathrm{~min}$ of coarctation and remained elevated at $45 \mathrm{~min}$ when compared with control rats. Overall, the results indicated that, in addition to the mechanical effect of aortic constriction, ANG II acts during the prompt $(5-15 \mathrm{~min})$ rise in pressure, whereas AVP is responsible for the maintenance (30-45 $\mathrm{min}$ ) of the arterial pressure elevation. Recently (27) it has been reported that elevated AVP may contribute to preoperative and postoperative hypertension in patients with chronic aortic coarctation.

Low renal perfusion pressure can trigger a sympathoexcitatory vasoconstrictor reflex (28-30). In our laboratory $(31,32)$ we studied the role of the sympathetic drive during aortic constriction by measuring the hypertensive response in conscious animals chronically (5 weeks) sympathectomized with guanethidine or acutely $(10 \mathrm{~min})$ treated with prazosin. Chronically sympathectomized rats exhibited a similar hypertensive response to aortic constriction as the control (intact sympathetic nervous system). On the other hand, prazosin did not affect the hypertensive response of intact animals. Taken together, these findings indicate that sympathetic activity does not play a role during aortic constriction, presumably due to the countereffect of the arterial (sinoaortic) baroreceptors mentioned above. It should be pointed out that baroreceptor activation reduces the sympathetic nerve activity on the vessels and the heart and increases vagal activity, producing a remarkable reflex bradycardia (33-35). The literature has reported more direct evidence of sympathetic inhibition during constriction of the aorta in anesthetized cats (36). These authors demonstrated that occlusion of the descending aorta inhibits renal sympathetic activity almost completely (98\%). Plasma norepinephrine concentration was consistently reduced, probably due to the countereffect of the sinoaortic baroreceptors. Nevertheless, in contrast to anesthetized dogs submitted to cross-clamping of the aorta $(24,37)$, plasma epinephrine concentration of conscious rats submitted to partial aortic constriction did not differ from that observed in their control counterparts. Similar findings were obtained in conscious dogs submitted to 24 to $48 \mathrm{~h}$ of aortic constriction (12). These data provided further evidence for an effective vasopressor role for AVP in the maintenance of acute (45 min) aortic coarctation hypertension in conscious rats. In addition, the results confirmed that the RAS participates earlier (15 min) in the onset of coarctation hypertension, but ruled out a significant vasopressor role for catecholamines.

Electrolytic lesion of the median eminence of the hypothalamus is a well-known experimental model of chronic as well as acute lack of vasopressin (38). In conscious rats submitted to previous (48 h) median eminence lesion of the hypothalamus, we investigated (39) the time course of action and the relative roles played by AVP and ANG II in the onset of the hypertensive response by means of pharmacological blockade of the pressor effect of these peptides with Manning's compound and saralasin, respectively. Lesioned rats exhibited a prompt rise in pressure in response to acute aortic constriction followed by a progressive decline, in contrast to sham-lesioned rats which exhibited a prompt hypertensive response which leveled off during the experiment (45 $\min )$. Lesioned rats treated with saralasin presented a blunted hypertensive response throughout the period of coarctation, whereas the sham-lesioned rats submitted to the same treatment presented only a delay in the onset of hypertension. Moreover, blockade of the $A V P V_{1}$ vascular receptors did not affect the hypertensive response of the lesioned rats, but elicited a progressive decline of the arterial pressure response of sham-lesioned rats. Collectively, these data demonstrated that the integrity of the median eminence of the hypothalamus plays a pivotal role in the maintenance (30-45 min) of acute aortic co- 
arctation hypertension, presumably involving the release of AVP from the neurohypophysis, whereas ANG II mainly accounts for the prompt (5-15 $\mathrm{min}$ ) rise in pressure.

It has become increasingly evident that the renal nerves contribute to the control of renal function and to homeostasis under normal conditions and are important in the pathogenesis of experimental hypertension $(40,41)$. It seems that the renal nerves are involved in the early stages of hypertension in the spontaneously hypertensive rat, whereas their importance in other forms of hypertension is controversial (42). There is evidence that afferent renal fibers carry mechanical and chemical information from the kidneys to specific brain nuclei which may influence the neurohumoral control of the kidney itself, or the circulation in general (43-45). It has been demonstrated that sensory information from the kidneys alters the release of AVP from the neurohypophysis, suggesting that afferent renal nerves are an important component of the neural circuitry controlling arterial pressure (46). Studies from our laboratory performed on conscious renaldenervated rats allowed us to investigate the contribution of sensory information originating in the kidneys to the release of AVP during an acute hypertensive response to partial aortic constriction (47). The hypertensive response observed in renal-denervated rats did not differ significantly from that observed in intact animals. Nevertheless, the previous intravenous administration of Manning's compound to renal-denervated rats did not affect the hypertensive response of these animals when compared to that of untreated renal-denervated subjects. Therefore, the lack of an effect of the $\mathrm{V}_{1}$ vascular receptor antagonist on the renaldenervated rats precludes a role for AVP in this response, presumably due to the absence of sensory information from the kidneys to the central nervous system (CNS) to trigger the release of AVP. In contrast, when renaldenervated rats were treated with saralasin, the hypertensive response following aortic constriction was significantly blunted throughout (45 min) the experiment. This finding was consistent with the hypothesis that only the RAS was playing a role in the hypertensive response of renal-denervated rats to aortic constriction. In addition, this finding indicates that blockade of the RAS in renal-denervated rats causes the mechanical component of the constriction to be the principal factor in the rise of the arterial pressure, as observed in anephric (16) and intact animals treated with Manning's compound plus saralasin (25). Moreover, the data obtained with renal-denervated rats treated with saralasin suggest that when one vasopressor system is hampered, as is the case for AVP due to the lack of signaling from the kidneys to the CNS, other mechanisms, e.g., the RAS, take over the major role in increasing the arterial pressure associated with the mechanical component of coarctation $(47,48)$. Although total renal denervation is not selective in eliminating renal sensory input to the CNS, affecting also efferent axons to the kidneys, data from our laboratory (47) have suggested that renal afferent feedback plays a role in the pathogenesis of aortic coarctation hypertension involving the release of AVP into the circulation.

It is well known that AVP release is controlled by osmotic and non-osmotic mechanisms. The stimuli for vasopressin release include an increase in plasma osmotic pressure, reduction in blood pressure and blood volume, nausea and pain (49). However, alternate pathways such as circulating ANG II (50-52) and renal afferences $(25,46,47,53)$ have been suggested to stimulate AVP release besides the well-known osmotic and non-osmotic mechanisms. More recently, experiments performed on chronic sinoaortic-denervated (SAD) rats and chronic nucleus tractus solitarius (NTS)-lesioned rats (54) have supported the hypothesis that when afferent stimuli from cardiovascular (arterial and cardiac) receptors are hampered, other 
mechanisms may take over the control of AVP release $(39,48,55)$.

In conclusion, the different approaches used in our laboratory to investigate the physiopathogenesis of acute (45 min) aortic coarctation hypertension, i.e., pharmacological blockade of AVP and ANG II (25), renal denervation (47), electrolytic lesions of the median eminence of the hypothalamus (39), and plasma hormone (AVP, PRA and catecholamines) assays (26), support the hypothesis that some territory below the coarctation is able to trigger the release of AVP into the circulation under special conditions such as low renal perfusion pressure, leading AVP to play a role in the hypertensive response during aortic constriction.

\section{Acknowledgments}

We thank J.A. Castania and M. Oliveira for expert technical assistance. We are also grateful to the co-authors of the papers from our laboratory dealing with the studies of aortic coarctation hypertension.

\section{References}

1. Blumgart HL, Lawrence JS \& Ernestene AC (1931). The dynamics of the circulation in coarctation of the aorta of the adult type. Archives of Internal Medicine, 47: 806-823.

2. Page IH (1940). The effect of chronic constriction of the aorta on arterial blood pressure in dogs: an attempt to produce coarctation of the aorta. American Heart Journal, 19: 218-232.

3. Bing RJ, Handelsman JC, Campbell JA, Griswold HE \& Blalock A (1948). The surgical treatment and the physiopathology of coarctation of the aorta. Annals of Surgery, 128: 803-824

4. Goldblatt H, Kahn JR \& Hanzal RF (1939). Studies on experimental hypertension. The effect on blood pressure of constriction of the abdominal aorta above and below the site of origin of both main renal arteries. Journal of Experimental Medicine, 69: 649-674.

5. Scott HW \& Bahnson HT (1951). Evidence for a renal factor in the hypertension of experimental coarctation of the aorta. Surgery, 30: 206-217.

6. Scott HW, Collins HA, Langa AM \& Olsen NS (1954). Additional observations concerning the physiology of the hypertension associated with experimental coarctation of the aorta. Surgery, 36: 445-459.

7. Habib WK \& Nanson EM (1968). The causes of hypertension in coarctation of the aorta. Annals of Surgery, 168: 771778 .

8. Ferguson JC, Barrie WW \& Schenk Jr WG (1977). Hypertension of aortic coarctation: The role of renal and other factors. Annals of Surgery, 185: 423-428.
9. Carretero OA \& Romero JC (1977). Production and characteristics of experimental hypertension in animals. In: Genest G, Koiw E \& Kuchel O (Editors), Hypertension. McGraw, New York, 485-507.

10. Eklof AC \& Aperia A (1989). Renal function in different forms of renovascular hypertension in rats. Acta Physiologica Scandinavica, 136: 487-492.

11. Eklof AC \& Aperia A (1990). Renal hypertension following aortic constriction is abolished by angiotensin I converting enzyme but not by low-salt diet. Acta Physiologica Scandinavica, 139: 435-440.

12. Whitlow PL \& Katholi RE (1983). Neurohumoral mechanisms in acute aortic coarctation in conscious and anesthetized dogs. American Journal of Physiology, 244: H614-H621.

13. Bagby SP \& Fuchs EF (1989). Chronic MK421 fails to modify evolution of hypertension in neonatally coarcted pups. Hypertension, 13: 91-101.

14. Stene JK, Burns B, Permutt S, Caldini P \& Shanoff M (1982). Increased cardiac output following occlusion of the descending thoracic aorta in dogs. American Journal of Physiology, 242: R152-R158.

15. Maio AA, Moreira ED, Salgado HC \& Krieger EM (1981). Cardiovascular responses of conscious rats due to arterial occlusion. Brazilian Journal of Medical and Biological Research, 14: 115 (Abstract).

16. Salgado HC \& Krieger EM (1986). Mechanical and renin-angiotensin system components in acute aortic coarctation hypertension. Hypertension, 8 (Suppl I): I.133-I.136
17. Fazan Jr R, Machado BH, Salgado MCO \& Salgado HC (1993). Effect of bilateral nephrectomy on hypertension produced by acute aortic coarctation. Brazilian Journal of Medical and Biological Research, 26 : 765-771.

18. DiBona GF (1982). The functions of the renal nerves. Reviews of Physiology, Biochemistry and Pharmacology, 94: 75-181.

19. Recordati GM, Moss NG \& Waselkov L (1978). Renal chemoreceptor in the rat. Circulation Research, 43: 534-543.

20. Recordati GM, Moss NG, Genovesi S \& Rogenes PR (1982). Renal receptors in the rat sensitive to chemical alterations of their environment. Circulation Research, 46: 395-405.

21. Day TA \& Ciriello J (1985). Afferent renal nerve stimulation excites supraoptic vasopressin neurons. American Journal of Physiology, 249: R1240-R1244.

22. Day TA \& Ciriello J (1987). Effect of renal receptor activation on neuro-secretory vasopressin cells. American Journal of Physiology, 253: R234-R241.

23. Yagi S, Kramsch DM, Madoff IM \& Hollander W (1968). Plasma renin activity in hypertension associated with coarctation of the aorta. American Journal of Physiology, 213: 605-610.

24. Symbas PN, Pfaender KM, Drucker MH, Lester JL, Gravanis MB \& Zacharopoulos $L$ (1983). Cross-clamping of the descending aorta. Journal of Thoracic and Cardiovascular Surgery, 85: 300-305.

25. Salgado HC \& Salgado MCO (1989). Acute aortic coarctation hypertension: role of vasopressin and angiotensin II. American Journal of Physiology, 257: H1480-H1484. 
26. Salgado HC, Skelton MM, Salgado MCO \& Cowley Jr AW (1994). Physiopathogenesis of acute aortic coarctation hypertension. Hypertension, 23 (Suppl I): I.78-I.81.

27. Stewart JM, Gewitz MH, Woolf PK, Niguidula F, Fish BG \& Zeballos GA (1995). Elevated arginine vasopressin and lowered atrial natriuretic factor associated with hypertension in coarctation of the aorta. Cardiovascular Surgery, 110: 900908.

28. Faber JE \& Brody MJ (1983). Neural contribution to renal hypertension following acute renal artery stenosis in conscious rats. Hypertension, 5: I.155-I.164.

29. Faber JE \& Brody MJ (1985). Afferent renal nerve-dependent hypertension following acute renal artery stenosis in conscious rat. Circulation Research, 57: 676688.

30. Faber JE \& Gettes DR (1987). Renal pressor reflex: involvement of sympathetic vasoconstrictor mechanisms. American Journal of Physiology, 252: H1147-H1158.

31. Fazan Jr R, Jorge $R$, Salgado MCO \& Salgado HC (1994). Aortic coarctation hypertension: role of the sympathetic nervous system in sinoaortic denervated (SAD) rats. Journal of Hypertension, 12 (Suppl 3): 557 (Abstract).

32. Fazan Jr R, Castania JA, Salgado MCO \& Salgado HC (1995). Sympathetic activity in conscious sinoaortic denervated rats submitted to aortic constriction. Hypertension, 25: 59 (Abstract).

33. Krieger EM, Salgado HC \& Michelini LC (1982). Resetting of baroreceptors. In: Guyton AC \& Hall JE (Editors), International Review of Physiology, 26. University Park Press, Baltimore.

34. Stornetta RL, Guyenet PG \& McCarty RC (1987). Autonomic nervous system control of heart rate during baroreceptor activation in conscious and anesthetized rats. Journal of the Autonomic Nervous System, 20: 121-127.

35. Schreihoffer AM \& Sved AF (1994). Use of sinoaortic denervation to study the role of baroreceptors in cardiovascular regulation. American Journal of Physiology, 266: R1705-R1710.
36. Ninomiya I \& Irisawa H (1969). Summation of baroreceptor reflex effects on sympathetic nerve activities. American Journal of Physiology, 216: 1330-1336.

37. Gelman S, Bredle DL, Bradley WE \& Cain SM (1990). Angiotensin and $\alpha$-adrenoceptor activation play a role in hemodynamic response to aortic cross-clamping. American Journal of Physiology, 259: H68-H73.

38. Crawford JD \& Frost LR (1963). A study of interphase in experimental diabetes insipidus. Endocrinology, 72: 677-683.

39. Fregoneze JB, Salgado MCO \& Salgado HC (1994). Effect of median eminence lesion on the hypertensive response due to acute aortic coarctation. American Journal of Physiology, 267: R762-R766.

40. Katholi RE (1983). Renal nerves in the pathogenesis of hypertension in experimental animals and humans. American Journal of Physiology, 245: F1-F14.

41. Wyss JM, Aboukarsh N \& Oparil S (1986). Sensory denervation of the kidney attenuates renovascular hypertension in the rat. American Journal of Physiology, 250: H82H86.

42. Kline RL (1987). Renal nerves and experimental hypertension: evidence and controversy. Canadian Journal of Physiology and Pharmacology, 65: 1540-1547.

43. Moss NG (1982). Renal function and renal afferent and efferent nerve activity. American Journal of Physiology, 243: F425-F433.

44. Oparil S, Sripairojhikoon W \& Wyss JM (1987). The renal afferent nerves in the pathogenesis of hypertension. Canadian Journal of Physiology and Pharmacology, 65: 1548-1558.

45. Stella A \& Zanchetti A (1991). Functional role of renal afferents. Physiological Reviews, 71: 659-682.

46. Caverson M \& Ciriello J (1987). Effect of stimulation of afferent renal nerves on plasma levels of vasopressin. American Journal of Physiology, 252: R801-R807.

47. Salgado HC, Fazan Jr R, Machado BH \& Salgado MCO (1992). Mechanical and neuro-humoral factors in acute aortic coarctation hypertension. Agents and Actions, 36: 152-163.
48. Fregoneze JB, Salgado MCO, Castro e Silva EJ \& Salgado HC (1995). Hypertensive response to acute aortic coarctation in chronic vasopressin deficient states. Clinical and Experimental Hypertension, 17: 977-988.

49. Share L (1996). Control of vasopressin release: an old but continuing story. News in Physiological Science, 11: 7-13.

50. Ferguson AV (1987). The subfornical organ: a central integrator in the control of neurohypophysial hormone secretion. In: Ciriello J, Caralesu FR, Renaud LP \& Polosa C (Editors), Organization of the Autonomic Nervous System: Central and Peripheral Mechanisms. Liss, New York, 435-445.

51. Ferguson AV \& Renaud LP (1987). Systemic angiotensin acts at subfornical organ to facilitate activity of neurohypophysial neurons. American Journal of Physiology, 251: R712-R717.

52. Knepel W, Nutto D \& Meyer DK (1982) Effect of transection of subfornical organ efferent projections on vasopressin release induced by angiotensin or isoprenaline in the rat. Brain Research, 248: 180184

53. Simon JK, Kasting NW \& Ciriello J (1989) Afferent renal nerve effects on plasma vasopressin and oxytocin in conscious rats. American Journal of Physiology, 256: R1240-R1244.

54. Schreihoffer AM, Stricker EM \& Sved AF (1994). Chronic nucleus tractus solitarius lesions do not prevent hypovolemia-induced vasopressin secretion in rats. American Journal of Physiology, 267: R965-R973.

55. Raff H (1994). Nonosmotic release of vasopressin: what are the afferent mechanisms? News in Physiological Science, 9: 281 